\title{
Blood Levels of Brain-Derived Neurotrophic Factor Correlate with Several Psychopathological Symptoms in Anorexia Nervosa Patients
}

Josep M. Mercader ${ }^{1}$, Fernando Fernández-Aranda ${ }^{2}$, Mònica Gratacòs ${ }^{1,3}$, Marta

Ribasés $^{1,4}$, Anna Badía ${ }^{2}$, Cynthia Villarejo ${ }^{2}$, Raquel Solano ${ }^{2}$, Juan R. González ${ }^{1,3}$, Julio Vallejo $^{2}$, Xavier Estivill ${ }^{1,3,5}$

1-Genes and Disease Program, Center for Genomic Regulation (CRG), and CIBER en Epidemiología y Salud Pública (CIBERESP).

2- Department of Psychiatry, University Hospital of Bellvitge, L’Hospitalet de Llobregat and CIBER. Fisiopatologia Obesidad y Nutricion (CIBEROBN), Instituto Salud Carlos III.

3- Barcelona Node, National Genotyping Center (CEGEN), Center for Genomic Regulation.

4- Department of Psychiatry, Hospital Universitari Vall d'Hebron

5- Experimental and Health Sciences Department, Pompeu Fabra University, Barcelona, Spain

\section{Corresponding author:}

Xavier Estivill, MD, PhD

Genes and Disease Program, Center for Genomic Regulation (CRG)

Charles Darwin s/n (Dr. Aiguader 88), PRBB Building, Room 521

ES-08003 Barcelona (Spain)

Tel. +34 93316 0138, Fax +34 93316 0099, E-Mail xavier.estivill@crg.es

\section{Key Words:}

Brain-derived neurotrophic factor_Eating disorders

Anorexia nervosa _ Bulimia nervosa _ Psychopathology _

Anxiety_Depression _ Obsessive-compulsiveness 


\section{Abstract}

Background: Evidence of a role of brain-derived neurotrophic factor (BDNF) in the pathophysiology of eating disorders (ED) has been provided by association studies and by murine models. BDNF plasma levels have been found altered in ED and in psychiatric disorders that show comorbidity with ED. Aims: Since the role of BDNF levels in ED-related psychopathological symptoms has not been tested, we investigated the correlation of BDNF plasma levels with the Symptom Checklist 90 Revised (SCL90R) questionnaire in a total of 78 ED patients. Methods: BDNF levels, measured by the enzyme-linked immunoassay system, and SCL-90R questionnaire, were assessed in a total of 78 ED patients. The relationship between BDNF levels and SCL-90R scales was calculated using a general linear model. Results: BDNF plasma levels correlated with the Global Severity Index and the Positive Symptom Distress Index global scales and five of the nine subscales in the anorexia nervosa patients. BDNF plasma levels were able to explain, in the case of the Psychoticism subscale, up to $17 \%$ of the variability $(\mathrm{p}=0.006)$. Conclusion: Our data suggest that BDNF levels could be involved in the severity of the disease through the modulation of psychopathological traits that are associated with the ED phenotype. 


\section{Introduction}

Anorexia nervosa (AN) and bulimia nervosa $(\mathrm{BN})$ are complex psychiatric conditions in which genetic and environmental factors are involved [1] . Among those genes with a role in satiety, appetite and weight regulation, brain-derived neurotrophic factor (BDNF) is widely accepted to participate in the pathophysiology of eating disorders (ED) [2-11] . BDNF protein levels have been studied for ED and other comorbid psychiatric disorders, such as schizophrenia, panic disorder and depression [12-17] . Results have revealed decreased BDNF blood levels in most disorders [18-20] . In the case of ED, however, contradictory results regarding BDNF levels have been reported $[4,10,11,21]$.

High levels of psychopathology traits in ED, such as depression, anxiety, impulsiveness and obsessionality,have been reported in the literature [22-24] and are linked to ED severity [25] and poorer prognosis [26].

To test if BDNF blood levels contribute to the phenotypic variability and severity of ED, possibly through the modulation of related psychopathological traits, we assessed the correlation between BDNF plasma levels and the Symptom Checklist 90 Revised (SCL-90R) psychometric parameters in a group of ED patients.

\section{Material and Methods}

\section{Subjects}

The clinical sample consisted of 78 Spanish Caucasian patients with ED consecutively admitted to the Psychiatric Unit of the Hospital de Bellvitge between 1999 and 2002. All patients were female, fulfilled DSM-IV criteria for ED and were diagnosed using 
the Structured Clinical Interview for Mental Disorders, research version 2.0 [27]. The study consisted of 44 AN (25 binge-eating purging AN and 19 restricting AN) and 33 purging BN patients. The lifetime minimum body mass index (BMI) was $15.3 \mathrm{~kg} / \mathrm{m} 2$ $(\mathrm{SD}=1.37)$ for $\mathrm{AN}$ patients and $19.2 \mathrm{~kg} / \mathrm{m} 2(\mathrm{SD}=2.8)$ for BN patients. The average age at assessment was 24.5 years $(\mathrm{SD}=6.0)$ for $\mathrm{AN}$ patients and 25.8 years $(\mathrm{SD}=5.0)$ for $\mathrm{BN}$ patients. The average age at onset of weight loss was 18.4 years $(\mathrm{SD}=4.3)$ for AN patients, and 18.5 years $(S D=4.6)$ for $B N$ patients.

Demographic-clinical information including age, weight, height and clinicalpsychopathological variables were also obtained. Additional demographic information on education, occupation and living arrangements was obtained via semistructured interview. Patients completed the SCL-90R interview, which is a widely used 90-item scale for assessing self-reported psychological distress and psychopathology [28, 29].

\section{SCL-90R Inventory}

The SCL-90R inventory measures a broad range of psychological problems and symptoms of psychopathology through three global indexes (Global Severity Index, Positive Symptom Distress Index and Positive Symptom Total) and nine primary symptom dimensions comprising a total of 83 items (Somatization, ObsessiveCompulsiveness, Interpersonal Sensitivity, Depression, Anxiety, Hostility, Phobic Anxiety, Paranoid Ideation and Psychoticism). The Global Severity Index, which is the participant's mean score (using all 90 items), is a widely used global index of distress. This scale has been validated in a Spanish population, obtaining a mean internal consistency of $0.75[30]$. 
Plasma was obtained by centrifugation from fresh peripheral blood samples and stored at $-20^{\circ} \mathrm{C}$ until used for the assay. BDNF levels were measured by the enzyme-linked immunoassay system (BDNF Emax Immunoassay System kit; Promega, Madison,

Wisc., USA). Patients were split into AN and BN as they might present different associated psychopathology [31]. A general linear model was used to test the link between BDNF blood levels and SCL-90R psychopathological traits, using R statistical package (http://www.r-project.org/).

\section{Results}

As it has been proposed that ED subtypes differ in physiological and psychological traits [32, 33], we decided to assess the correlation between BDNF plasma levels and the different ED-related phenotypes by splitting the patients into the two main clinical subtypes, AN and BN. A general linear model was used to assess all the correlations and R2 as a measure of the variance that is explained by the model. BDNF plasma levels did not correlate with BMI, minimum BMI or maximum BMI in any of the clinical subgroups, which rules out the possibility that BDNF is involved in the regulation of these physiological traits (data not shown). No differences were observed between the two subgroups of AN, binge-eating purging AN or restricting AN (t test, p value $=0.7)$. Nutritional state was also established by measuring the prealbumin concentration. No correlation was found between BDNF levels and prealbumin levels (data not shown). Neither actual BMI nor prealbumin levels were found to correlate with any of the SCL-90R items (data not shown).

We found that BDNF levels were negatively correlated with the Global Severity Index $\left(\mathrm{R}^{2}=0.12 ; \mathrm{p}=0.023\right)$ and the Positive Symptom Distress Index $\left(\mathrm{R}^{2}=0.14 ; \mathrm{p}=0.013\right)$ 
in the subgroup of AN patients. Once we considered the different SCL-90R subscales, we found negative correlations between BDNF plasma levels and ObsessiveCompulsiveness $\left(\mathrm{R}^{2}=0.13 ; \mathrm{p}=0.015\right)$, Interpersonal Sensititivy $\left(\mathrm{R}^{2}=0.12 ; \mathrm{p}=0.022\right)$, Depression $(\mathrm{R} 2=0.12 ; \mathrm{p}=0.021)$, Anxiety $(\mathrm{R} 2=0.15 ; \mathrm{p}=0.009)$, and Psychoticism $(\mathrm{R} 2=0.17 ; \mathrm{p}=0.006)$ (fig. 1$)$

\section{Discussion}

Some psychopathological traits and comorbid disorders, which persist after normalization of body weight and have strong heritability, could influence the susceptibility to both AN and BN. In agreement with our results, it has been described that serum BDNF levels are decreased in untreated major depression patients and the severity of the depression negatively correlates with BDNF levels, which in turn increases with medication response [34, 35]. A significant negative correlation between BDNF levels and the Hamilton Depression Rating Scale has also been reported [36]. BDNF serum concentration has been found to negatively correlate with the depressionrelated factor neuroticism [37]. We have recently reported increased BDNF levels for ED [11]. Moreover, high comorbidity between ED and Axis I or Axis II disorders, such as affective disorders, personality disorders, anxiety disorders, obsessive compulsive disorders, impulse control disorders and substance abuse, has been described [13-17, 22-24]. Accordingly, the degree of comorbidity could be modulated by BDNF expression levels. As some authors have suggested, a link between internalizing syndromes (e.g. social anxiety, obsessionality) and AN is more prevalent [31, 38], whereas externalizing symptoms (e.g. self-harm and self-injurious behaviors, drug and alcohol abuse) and higher psychopathological traits, namely depression, general anxiety and impulsivity are more frequent among BN patients [23, 24]. It might 
be suggested that levels of BDNF may function as a mediator of these psychopathological traits, influencing the outcome and the prognosis of the patient. This study has some limitations that have to be considered. First, we measured plasma concentrations, which have low correlation with serum BDNF levels [39]. While potential sources of plasma BDNF include endothelial and smooth muscle cells [4042], activated macrophages or lymphocytes [41, 43, 44], and neurons and glia cells from the central nervous system [45-47], most BDNF in serum likely reflects the amount of BDNF accumulated in platelets, which is released during the clotting process [48]. Thus, the interpretation of changes in BDNF plasma levels should be taken with caution when comparing with results of other groups that studied serum BDNF in different pathologies. Second, the lack of significant results in the BN group could be due to the limited sample size and hence the reduced statistical power. Third, we did not consider ED clinical categories to correct for multiple testing, as it might be too stringent to detect a moderate correlation with different endophenotypes, taking into account that the different ED subtypes and SCL-90R are not independent factors, a requirement for the application of Bonferroni correction.

Even though BDNF plasma levels have been previously reported to be decreased in healthy sisters of 50 of the ED patients included in the present study [11], we have not been able to test BDNF correlation with SCL-90R scales, as this questionnaire was not evaluated in healthy sisters. The correlation of BDNF plasma levels and SCL90 symptoms in controls or in patients recovered from the disease should be evaluated in order to assess if it follows the same trend observed in our patients and therefore disclose whether the correlation is diagnosis-specific or not. Lastly, the possibility that 
other influencing factors related to weight reduction are correlated with BDNF cannot be ruled out, although the lack of correlation between BMI and SCL-90R or BDNF makes it quite unlikely.

To our knowledge, this is the first study that assesses the relationship between EDrelated psychopathological traits and BDNF blood levels in ED patients, although the results should be taken with caution until replicated in a larger sample. We also confirm the correlation of depressive symptoms in our sample, and give some insights into other psychopathological traits that might be modulated by BDNF. In summary, we propose that BDNF levels could act as modulators of ED psychopathological traits, although these results should be replicated in a larger sample, before considering BDNF plasma levels as a possible marker of the severity of the disease.

\section{Acknowledgements}

We thank the patients for participation in the study, and Carolina Casanovas and Araceli Núñez for their help on collecting the data. Financial support was received from the Psychiatry Genetics Network (G03/184, Carlos III Research Institute), the Ministry of Education and Science (SAF2005-01005), the 'Fondo de Investigaciones Sanitarias de la Seguridad Social, FIS (PI40632 and PI052307) and FIS (PI040619; CIBERCB06/03/0034), the Department of Health (Generalitat de Catalunya), and the Department of Universities, Research and Information Society (2005SGR00008; 2005SGR322, Generalitat de Catalunya). Josep M. Mercader was supported by the CRG (project SAF2002-00799, Spanish Ministry of Science and Education), and by a fellowship of the Danone Institute. Marta Ribases received a BEFI fellowship from the FIS (Spanish Ministry of Health). 


\section{References}

1 Fairburn CG, Harrison PJ: Eating disorders.

Lancet $2003 ; 361: 407-416$.

2 Ribases M, Gratacos M, Armengol L, de Cid R, Badia A, Jimenez $\mathrm{L}$, Solano R, Vallejo J, Fernandez F, Estivill X: Met66 in the brain-derived neurotrophic factor (BDNF) precursor is associated with anorexia nervosa restrictive type. Mol Psychiatry 2003; 8: 745-751.

3 Ribases M, Gratacos M, Fernandez-Aranda F, Bellodi L, Boni C, Anderluh M, Cavallini MC, Cellini E, Di Bella D, Erzegovesi S, Foulon C, Gabrovsek M, Gorwood P, Hebebrand J, Hinney A, olliday $\mathrm{J}$, Hu X, Karwautz A, Kipman A, Komel R, Nacmias B, Remschmidt H, Ricca V, Sorbi S, Wagner G, Treasure J, Collier DA, Estivill $X$ : Association of BDNF with anorexia, bulimia and age of onset of weight loss in six European populations. Hum Mol Genet 2004; $13: 1205-1212$.

4 Nakazato M, Hashimoto K, Shimizu E, Kumakiri C, Koizumi H, Okamura N, Mitsumori M, Komatsu N, Iyo M: Decreased levels of serum brain-derived neurotrophic factor in female patients with eating disorders. Biol Psychiatry 2003; 54:485-490. 5 Koizumi H, Hashimoto K, Itoh K, Nakazato M, Shimizu E, Ohgake S, Koike K, Okamura N, Matsushita S, Suzuki K, Murayama M, Higuchi S, Iyo M: Association between the brain-derived neurotrophic factor 196G/A polymorphism and eating disorders. Am J Med Genet 2004; 127B:125-127.

6 Hashimoto K, Koizumi H, Nakazato M, Shimizu E, Iyo M: Role of brain-derived neurotrophic factor in eating disorders: recent findings and its pathophysiological implications. Prog Neuropsychopharmacol Biol Psychiatry 2005; 29: 499-504. 7 Gratacos M, Gonzalez JR, Mercader JM, de Cid R, Urretavizcaya M, Estivill X: Brain-derived neurotrophic factor Val66Met and psychiatric disorders: meta-analysis of case-control studies confirm association to sub-stance-related disorders, eating disorders, and schizophrenia. Biol Psychiatry 2007; 61: 911-922.

8 Ribases M, Gratacos M, Fernandez-Aranda F, Bellodi L, Boni C, Anderluh M, Cristina Cavallini M, Cellini E, Di Bella D, Erzegovesi S, Foulon C, Gabrovsek M, Gorwood P, Hebebrand J, Hinney A, Holliday J, Hu X, Karwautz A, Kipman A, Komel R, Nacmias B, Remschmidt H, Ricca V, Sorbi S, Tomori M, wagner G, Treasure J, Collier DA, Estivill X: Association of BDNF with restricting anorexia nervosa and minimum body mass index: a family-based association study of eight European populations. Eur J Hum Genet 2005;13:428-434.

9 Ribases M, Gratacos M, Badia A, Jimenez L, Solano R, Vallejo $\mathrm{J}$, Fernandez-Aranda F, Estivill X: Contribution of NTRK2 to the genetic susceptibility to anorexia nervosa, harm avoidance and minimum body mass index. Mol Psychiatry 2005; 10:851-860.

10 Monteleone P, Fabrazzo M, Martiadis V, Serritella C, Pannuto M, Maj M: Circulating brain-derived neurotrophic factor is decreased in women with anorexia and bulimia nervosa but not in women with binge-eating disorder: relationships to co-morbid depression, psychopathology and hormonal variables.

Psychol Med 2005; 35:897-905. 
11 Mercader JM, Ribasés M, Gratacòs M, González JR, Bayés M, de Cid R, Badía A, Fernández-Aranda F, Estivill X: Altered brainderived neurotrophic factor blood levels and gene variability are associated with anorexia and bulimia. Genes Brain Behav $2007 ; 6: 706-716$.

12 Bulik CM, Klump KL, Thornton L, Kaplan AS, Devlin B, Fichter MM, Halmi KA, Strober M, Woodside DB, Crow S, Mitchell JE, Rotondo A, Mauri M, Cassano GB, Keel PK, Berrettini WH, Kaye WH: Alcohol use disorder comorbidity in eating disorders: a multicenter study. J Clin Psychiatry 2004; 65: 1000-1006.

13 Godart NT, Flament MF, Lecrubier $Y$, Jeammet P: Anxiety disorders in anorexia nervosa and bulimia nervosa: co-morbidity and chronology of appearance. Eur Psychiatry 2000;15:38-45. 14 Grilo CM, Sanislow CA, Skodol AE, Gunderson JG, Stout RL, Shea MT, Zanarini MC, Bender DS, Morey LC, Dyck IR, McGlashan TH: Do eating disorders co-occur with personality disorders? Comparison groups matter. Int J Eat Disord 2003; 33:155-164. 15 Milos G, Spindler A, Schnyder U: Psychiatric comorbidity and Eating Disorder Inventory (EDI) profiles in eating disorder patients. Can J Psychiatry 2004; 49:179-184.

16 Kaye WH, Bulik CM, Thornton L, Barbarich N, Masters K: Comorbidity of anxiety disorders with anorexia and bulimia nervosa. Am J Psychiatry 2004; 161:2215-2221.

17 Steiger $H$, Gauvin L, Engelberg MJ, Ying Kin NM, Israel M, Wonderlich SA, Richardson J: Mood- and restraint-based

antecedents to binge episodes in bulimia nervosa: possible influences of the serotonin system. Psychol Med 2005; 35:15531562 .

18 Neumeister A, Yuan P, Young TA, Bonne 0, Luckenbaugh DA, Charney DS, Manji H: Effects of tryptophan depletion on serum levels of brain-derived neurotrophic factor in unmedicated patients with remitted depression and healthy subjects. Am J Psychiatry 2005; 162:805-807.

19 Tan YL, Zhou DF, Cao LY, Zou YZ, Zhang XY: Decreased BDNF in serum of patients with chronic schizophrenia on long-term treatment with antipsychotics. Neurosci Lett 2005;382:27-32. 20 Karege F, Bondolfi G, Gervasoni N, Schwald M, Aubry JM, Bertschy G: Low brain-derived neurotrophic factor (BDNF) levels in serum of depressed patients probably results from lowered platelet BDNF release unrelated to platelet reactivity. Biol Psychiatry 2005; 57: 1068-1072.

21 Monteleone P, Tortorella A, Martiadis V, Serritella C, Fuschino A, Maj M: opposite changes in the serum brain-derived neurotrophic factor in anorexia nervosa and obesity. Psychosom Med 2004; 66:744-748.

22 Bulik CM, Tozzi F: Genetics in eating disorders: state of the science. CNS Spectr 2004; 9: 511-515.

23 Fernandez-Aranda F, Jimenez-Murcia S, Alvarez-Moya EM, Granero R, Vallejo J, Bulik CM: Impulse control disorders in eating disorders: clinical and therapeutic implications. Compr Psychiatry 2006; 47: 482-488. 
24 Fernandez-Aranda F, Pinheiro AP, Tozzi F, Thornton LM, Fichter MM, Halmi KA, Kaplan AS, Klump KL, Strober M, Woodside DB, Crow S, Mitchell J, Rotondo A, Keel P,Plotnicov KH, Berrettini $W H$, Kaye WH, Crawford SF, Johnson $C$, Brandt $H$, La Via $M$, Bulik CM: Symptom profile of major depressive disorder in women with eating disorders. Aust NZ J Psychiatry 2007; 41:2431.

25 McDermott B, Forbes D, Harris C, McCormack J, Gibbon P: Noneating disorders psychopathology in children and adolescents with eating disorders: implications for malnutrition and symptom severity. J Psychosom Res 2006; 60:257-261.

26 Ro 0, Martinsen EW, Hoffart A, Rosenvinge JH: Short-term follow-up of adults with long standing anorexia nervosa or nonspecified eating disorder after inpatient treatment. Eat Weight Disord 2004; 9:62-68.

27 First M, Gibbon M, Spitzer R, J W: Users Guide for the Structured Clinical Interview for DSM IV Axis I Disorders, research version (SCID-I, version 2.0). New York, New York State Psychiatric Institute, 1996.

28 Derogatis LR, Melisaratos N: The Brief Symptom Inventory: an introductory report. Psychol Med 1983; 13:595-605.

29 Derogatis LR: A Bibliography of Research Reports 1975-1990. Baltimore, Clinical Psychometric Research, 1990.

30 Derogatis LR: Cuestionario de 90 síntomas: Manual. Madrid, TEA Editorial, 2002.

31 Verona E, Sachs-Ericsson N, Joiner TE Jr: Suicide attempts associated with externalizing psychopathology in an

epidemiological sample. Am J Psychiatry 2004; 161:444-451.

32 Association AP: DSM-IV: Diagnostic and Statistical Manual of Mental Disorders. Washington, The American Psychiatric association, 1994.

33 Fassino S, Abbate-Daga G, Amianto F, Leombruni P, Boggio S, Rovera GG: Temperament and character profile of eating disorders: a controlled study with the Temperament and Character Inventory. Int $\mathrm{J}$ Eat Disord 2002;32:412-425.

34 Shimizu E, Hashimoto K, Okamura N, Koike K, Komatsu N, Kumakiri C, Nakazato M, Watanabe $H$, Shinoda N, Okada S, Iyo M: Alterations of serum levels of brain-derived neurotrophic factor (BDNF) in depressed patients with or without antidepressants. Biol Psychiatry 2003; 54:70-75.

35 Aydemir 0, Deveci A, Taneli F: The effect of chronic antidepressant treatment on serum brain-derived neurotrophic factor levels in depressed patients: a preliminary study. Prog Neuropsychopharmacol Biol Psychiatry 2005;29: 261-265. 36 Karege F, Perret G, Bondolfi G, Schwald M, Bertschy G, Aubry JM: Decreased serum brain-derived neurotrophic factor levels in major depressed patients. Psychiatry Res 2002;109:143-148.

37 Lang UE, Hellweg R, Gallinat J: BDNF serum concentrations in healthy volunteers are associated with depression-related personality traits. Neuropsychopharmacology 2004;29: 795-798. 38 Jimenez-Murcia S, Fernandez-Aranda F, Raich RM, Alonso P, Krug I, Jaurrieta N, Alvarez-Moya E, Labad J, Menchon JM, Vallejo J: Obsessive-compulsive and eating disorders: comparison of clinical and personality features. Psychiatry Clin Neurosci 2007;61: 385-391. 
39 Lommatzsch M, Zingler D, Schuhbaeck K, Schloetcke K, Zingler $C$, Schuff-Werner P, Virchow JC: The impact of age, weight and gender on BDNF levels in human platelets and plasma. Neurobiol Aging 2005; 26:115-123.

40 Donovan MJ, Miranda RC, Kraemer R, Mc-Caffrey TA, Tessarollo L, Mahadeo D, Sharif S, Kaplan DR, Tsoulfas P, Parada L, et al: Neurotrophin and neurotrophin receptors in vascular smooth muscle cells. Regulation of expression in response to injury. Am J Pathol 1995; 147:309-324.

41 Braun A, Lommatzsch M, Mannsfeldt A, Neuhaus-Steinmetz $U$, Fischer A, Schnoy N, Lewin GR, Renz H: Cellular sources of enhanced brain-derived neurotrophic factor production in a mouse model of allergic inflammation. Am J Respir Cell Mol Biol 1999; 21:537-546.

42 Nakahashi T, Fujimura H, Altar CA, Li J, Kambayashi J, Tandon NN, Sun B: Vascular endothelial cells synthesize and secrete brain-derived neurotrophic factor. FEBS Lett 2000; 470:113-117. 43 Gielen A, Khademi M, Muhallab S, Olsson T, Piehl F: Increased brain-derived neurotrophic factor expression in white blood cells of relapsing-remitting multiple sclerosis patients. Scand J Immunol 2003; 57: 493-497.

44 Kerschensteiner M, Gallmeier E, Behrens L, Leal VV, Misgeld $\mathrm{T}$, Klinkert WE, Kolbeck R, Hoppe E, Oropeza-Wekerle RL, Bartke I, Stadelmann C, Lassmann $H$, Wekerle $H$, Hohlfeld R: Activated human T cells, B cells, and monocytes produce brain-derived neurotrophic factor in vitro and in inflammatory brain lesions: a neuroprotective role of inflammation? J Exp Med 1999; 189:865870 .

45 Karege F, Schwald M, Cisse M: Postnatal developmental profile of brain-derived neurotrophic factor in rat brain and platelets. Neurosci Lett 2002; 328:261-264.

46 Pan W, Banks WA, Fasold MB, Bluth J, Kastin AJ: Transport of brain-derived neurotrophic factor across the blood-brain barrier. Neuropharmacology 1998;37:1553-1561.

47 Phillips HS, Hains JM, Laramee GR, Rosenthal A, Winslow JW: Widespread expression of BDNF but not NT3 by target areas of basal forebrain cholinergic neurons. Science 1990;250:290-294. 48 Fujimura $\mathrm{H}$, Altar CA, Chen R, Nakamura T, Nakahashi T, Kambayashi J, Sun B, Tandon NN: Brain-derived neurotrophic factor is stored in human platelets and released by agonist stimulation. Thromb Haemost 2002; 87: 728-734. 


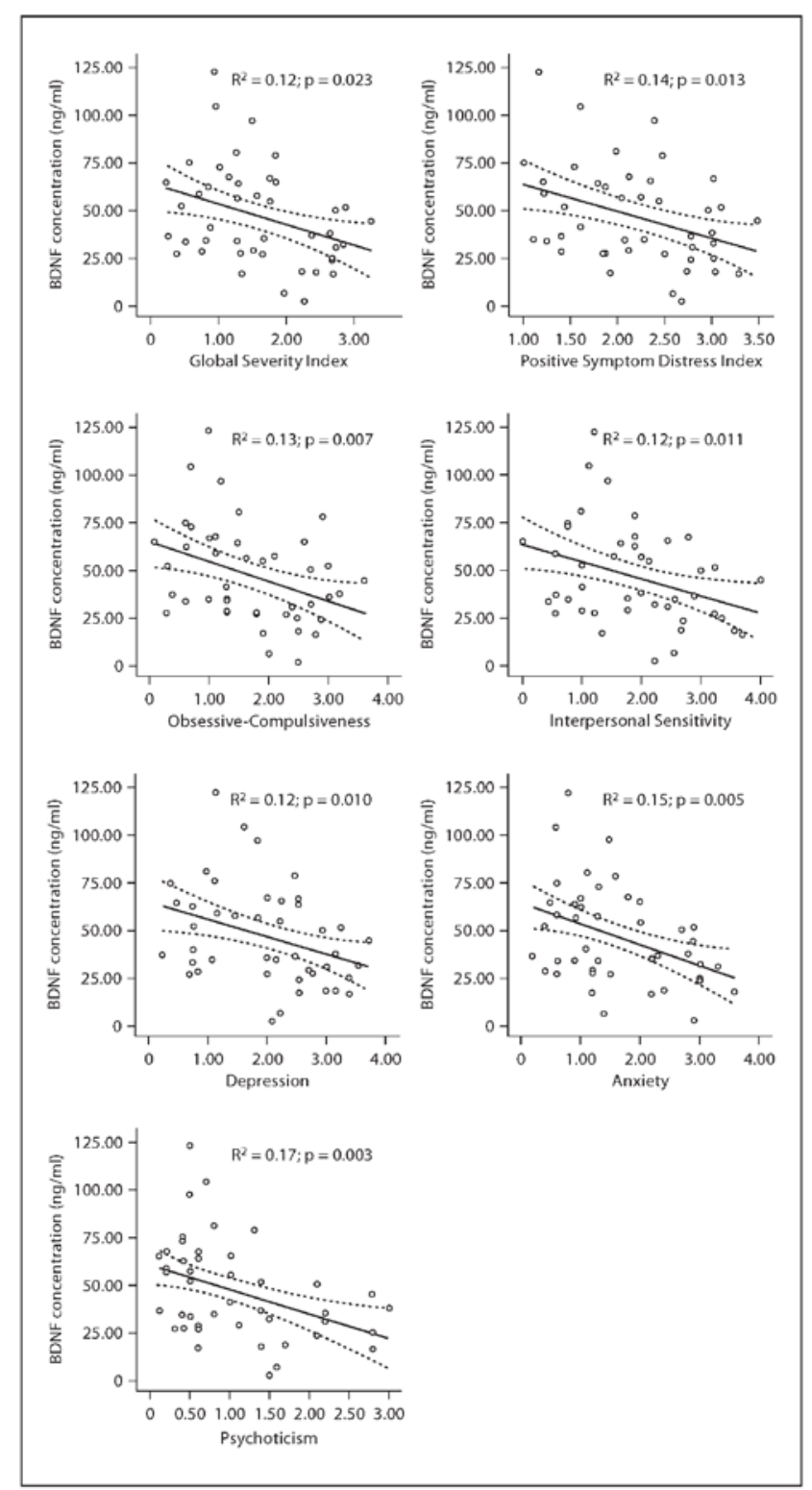

Fig. 1. Dot plot representing the correlation between blood levels and several SCL-90R symptom scales. $\mathrm{R}^{2}$ was calculated using a general linear model (GLM). 